NASA/CR-1998-208720

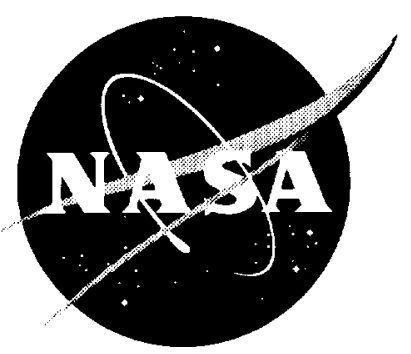

\title{
Fabrication and Testing of a Leading-Edge-Shaped Heat Pipe
}

David E. Glass

Analytical Services \& Materials, Inc., Hampton, Virginia

Michael A. Merrigan, J. Tom Sena, and Robert S. Reid

Los Alamos National Laboratory, Los Alamos, New Mexico

National Aeronautics and

Space Administration

Langley Research Center

Hampton, Virginia 23681-2199

Prepared for Langley Research Center under Contract NAS1-96014 
The use of trademarks or names of manufacturers in this report is for accurate reporting and does not constitute an official endorsement, either expressed or implied, of such products or manufacturers by the National Aeronautics and Space Administration or by Analytical Services \& Materials, Inc.

Available from:

NASA Center for AeroSpace Information (CASI)

7121 Standard Drive

Hanover, MD 21076-1320

(301) 621-0390
National Technical Information Service (NTIS) 5285 Port Royal Road

Springfield, VA 22161-2171

(703) 605-6000

Available electronically at the following URL address: http://techreports.larc.nasa.gov/ltrs 


\title{
Fabrication and Testing of a
}

\section{Leading-Edge-Shaped Heat Pipe}

\author{
David E. Glass* \\ Analytical Services \& Materials, Inc., Hampton, VA 23666 \\ Michael A. Merrigan, J. Tom Sena, and Robert S. Reid \\ Los Alamos National Laboratory, Los Alamos, NM 87545
}

\begin{abstract}
A leading-edge-shaped heat pipe was successfully fabricated and tested. The heat pipe had a "D-shaped" cross section and was fabricated from arc cast molybdenumrhenium. An artery was included in the wick. Several issues were resolved during the fabrication of the heat-pipe container and wick with a sharp-leading-edge radius. The heat pipe was tested in a vacuum chamber using induction heating and was started up from the frozen state several times. The heat pipe did operate as a heat pipe over a portion of its length. However, design temperatures and heat fluxes were not obtained due to premature failure of the heat pipe resulting from electrical discharge between the induction heating apparatus and the heat pipe.
\end{abstract}

\section{Introduction}

Stagnation regions, such as wing and tail leading edges and nose caps, are critical design areas of hypersonic aerospace vehicles because of the hostile thermal environment those regions experience during flight. As a hypersonic vehicle travels through the earth's atmosphere, the high local heating and aerodynamic forces cause very high temperatures, severe thermal gradients, and high stresses. Analytical studies and laboratory and wind tunnel tests indicate that a solution to the thermal-structural problems associated with stagnation regions of hypersonic aerospace vehicles might be obtained by the use of heat pipes to cool these regions.

In the early 1970's, several feasibility studies were performed to assess the application of heat pipes for cooling leading edges and nose caps of hypersonic vehicles. ${ }^{1-}$ 5 NASA Langley Research Center (LaRC), through a contractual study, analytically verified the viability of heat pipes for cooling stagnation regions of hypersonic vehicles. ${ }^{1}$ In 1972, McDonnell Douglas Astronautics Co. (MDAC) compared four space shuttle

\footnotetext{
"Phone: (757) 864-5423, e-mail: d.e.glass@larc.nasa.gov
} 
wing leading-edge concepts: a passive carbon-carbon concept, a passive coatedcolumbium concept, an ablative concept, and a liquid-metal/superalloy heat-pipe-cooled concept. $^{2}$ The heat-pipe-cooled concept was determined to be a feasible and durable design concept, but was slightly heavier than the other candidate concepts. In 1973, MDAC fabricated a half-scale shuttle-type heat-pipe-cooled leading edge to verify feasibility of the concept. ${ }^{4}$ This model was tested by a series of radiant heat and aerothermal tests at NASA LaRC from 1977 to 1978 to verify heat-pipe transient, startup, and steady-state performance. ${ }^{6-8}$ In 1979 , MDAC received a follow-on contract to optimize a heat-pipe-cooled wing leading edge for a single-stage-to-orbit vehicle. Results of the follow-on study indicated that the mass of a shuttle-type heat-pipe-cooled leading edge could be reduced by over $40 \%$ by use of a more efficient structural design. ${ }^{9}$ In $1986 \mathrm{MDAC}$ received a contract to design and fabricate a sodium/superalloy heatpipe-cooled leading edge component for an advanced shuttle-type vehicle. ${ }^{10}$ This advanced shuttle-type heat pipe was 6-ft long and was tested at MDAC by radiant heating and at Los Alamos National Laboratory (LANL) by induction heating. ${ }^{11-12}$

A Haynes 25/sodium leading-edge-shaped heat pipe with a "D-shaped" cross section was designed and tested by Boeing Advanced Systems. ${ }^{13}$ The heat pipe had a length of $11.8 \mathrm{in}$., and a wall thickness of 0.030 in. Thermal performance, vibration sensitivity, and critical heat flux tests were conducted. Straight niobium/lithium heat pipes with a "D-shaped" cross section and a 0.024 in. thick wall have also been fabricated and tested. ${ }^{14-15}$ These heat pipes had an oxidation resistance coating on the outer surface. Each of the heat pipes in references 13-15 utilized a sintered metal wick.

Preliminary design studies at NASA LaRC indicate that a refractorycomposite/refractory-metal heat-pipe-cooled leading edge can reduce the leading-edge mass by over $50 \%$ compared to an actively cooled leading edge, can completely eliminate the need for active cooling, and has the potential to provide failsafe and redundant features. ${ }^{16}$ Recent work to develop this novel refractory-composite/refractory-metal heatpipe-cooled leading edge for hypersonic vehicles combines advanced high-temperature materials, coatings, and fabrication techniques with an innovative thermal-structural design. Testing of a component at NASA LaRC with three straight molybdenumrhenium (Mo-Re) heat pipes embedded in carbon/carbon $(\mathrm{C} / \mathrm{C})$ has demonstrated the feasibility of operating heat pipes embedded in $\mathrm{C} / \mathrm{C} \cdot{ }^{17-18}$ In those tests, the heat pipes were tested with quartz lamps up to temperatures around $2200^{\circ} \mathrm{F}$. Some of key concepts utilized in the fabrication of the refractory composite heat-pipe-cooled leading edge, such as a compliant or removable layer to reduce thermal stresses and a slightly convex surface to maintain good thermal contact, have been patented. ${ }^{19}$

The present paper discusses the next step in the development of a refractorycomposite/refractory-metal heat-pipe-cooled leading edge: a leading-edge-shaped heat pipe with a relatively sharp leading edge and a thin wall thickness. Numerous fabrication issues were resolved in the fabrication of both the heat-pipe container and wick. The heat pipe was fabricated from arc cast Mo-41Re, used lithium as the working fluid, and had a "D-shaped" cross-section. The heat-pipe wick was constructed with 400 x 400 mesh Mo$5 \operatorname{Re}$ screen with a single artery along the length of the heat pipe. The heat pipe was tested in a vacuum chamber at LANL using induction heating. 


\section{Description of Heat-Pipe-Cooled Leading-Edge Concept}

Heat pipes have been considered for use on leading edges of hypersonic vehicles. A brief description of how heat pipes operate and are applied for leading-edge cooling is first presented, followed by a description of the proposed heat-pipe-cooled leading-edge concept.

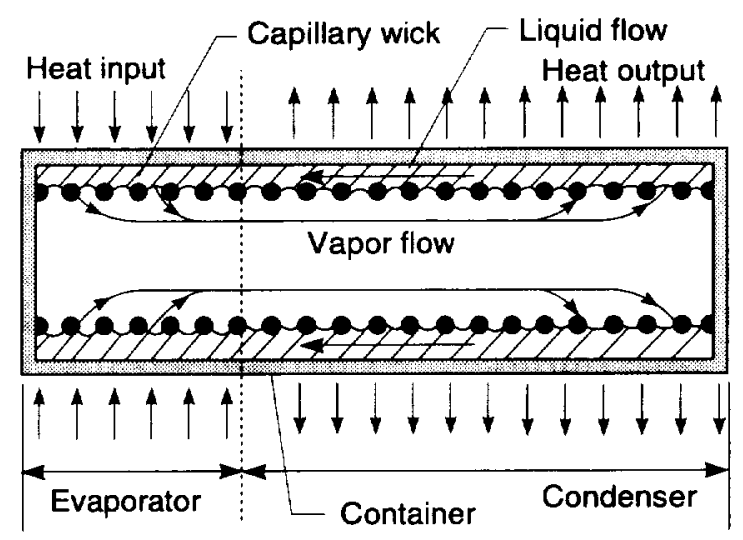

Figure 1: Schematic diagram of the operation of a heat pipe showing the heat-pipe container, working fluid, and wick.

\section{Leading-Edge Heat-Pipe Operation}

Heat pipes transfer heat nearly isothermally by the evaporation and condensation of a working fluid, as illustrated in Figure 1. The heat is absorbed within the heat pipe by evaporation of the working fluid. The evaporation results in a slight internal pressure differential that causes the vapor to flow from the evaporator region to the condenser region, where it condenses and gives up heat. The cycle is completed with the return flow of the liquid condensate to the evaporator region by the capillary action of a wick.

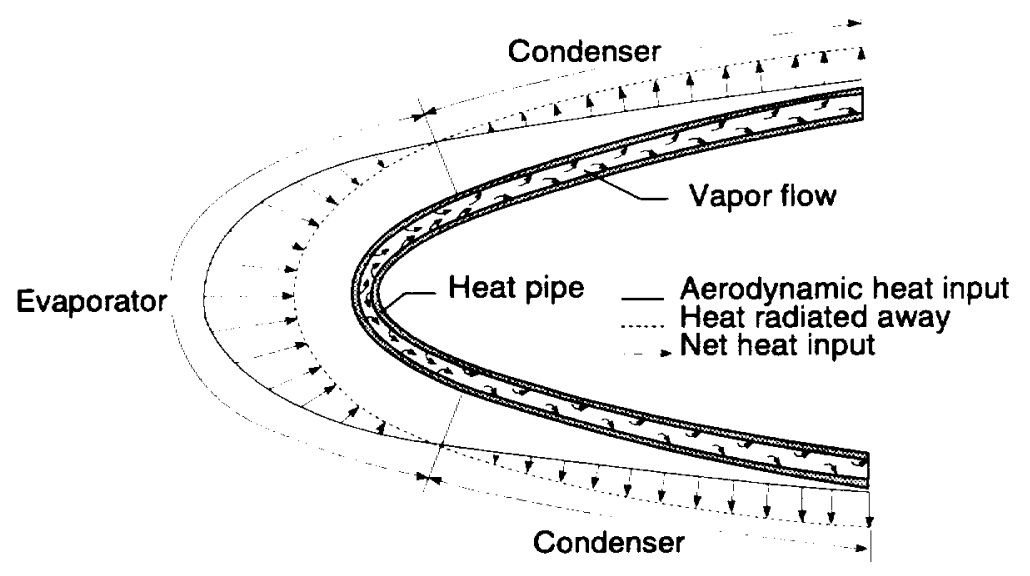

Figure 2: Schematic diagram of a heat-pipe-cooled leading edge showing regions of net heat input (evaporator) and net heat output (condenser). 
Heat pipes provide cooling of stagnation regions by transferring heat nearly isothermally to locations aft of the stagnation region, thus raising the temperature aft of the stagnation region above the expected radiation equilibrium temperature. When applied to leading-edge cooling, heat pipes operate by accepting heat at a high rate over a small area near the stagnation region and radiating it at a lower rate over a larger surface area, as shown in Figure 2. The use of heat pipes results in a nearly isothermal leadingedge surface, thus reducing the temperatures in the stagnation region and raising the temperatures of both the upper and lower aft surfaces.

\section{Refractory Composite Heat-Pipe-Cooled Wing-Leading-Edge}

The refractory composite heat-pipe-cooled wing-leading-edge concept is illustrated in Figure 3. The heat pipes are oriented normal to the leading edge and have a " $\mathrm{D}$ shaped" cross section, with the flat part of the " $\mathrm{D}$ " forming the wing-leading-edge outer surface. The leading edge comprises "J-tube" heat pipes, with a "J-tube" heat pipe being a heat pipe with a long leg on one side of the nose region, and a short leg on the other side of the nose region, as shown in Figure 3. An alternating "J-tube" configuration was selected to minimize heat-pipe spacing in the nose region where heating is the highest, provide a greater heat-pipe spacing on the upper and lower surfaces where heating is lower, and at the same time minimize mass. The refractory composite structure sustains most of the mechanical structural loads and also offers ablative protection in the event of a heat-pipe failure.
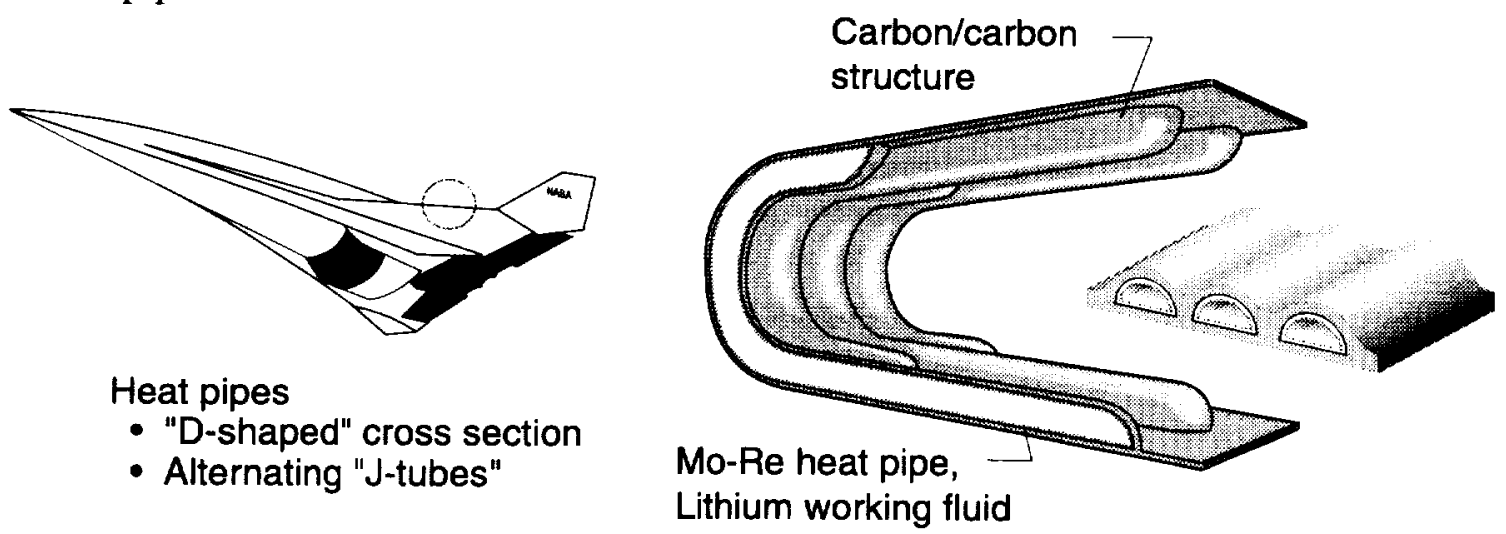

Figure 3: Schematic drawing of a hypersonic vehicle with a diagram of a heat-pipecooled wing leading edge.

The maximum operating temperature capability of coated refractory-composite materials for the primary structure of the leading edge is high $\left(\sim 3000^{\circ} \mathrm{F}\right)$ relative to refractory metals, which are typically limited to approximately $2400^{\circ} \mathrm{F}$. The potentially higher operating temperature increases the radiation heat-rejection efficiency of the heatpipe-cooled leading edge and permits reductions in the mass of the leading edge for a given leading-edge radius. In addition, the higher operating temperature increases the total heat load that can be accommodated passively by the heat pipe (i.e., no forced convective cooling required). For many trajectories, the high operating temperatures help eliminate the need for active cooling during both ascent and descent, thus eliminating the need for carrying additional hydrogen fuel (coolant) into orbit. Since many hypersonic 
vehicles return unpowered for landing, the additional hydrogen fuel needed for cooling during descent would result in a mass penalty.

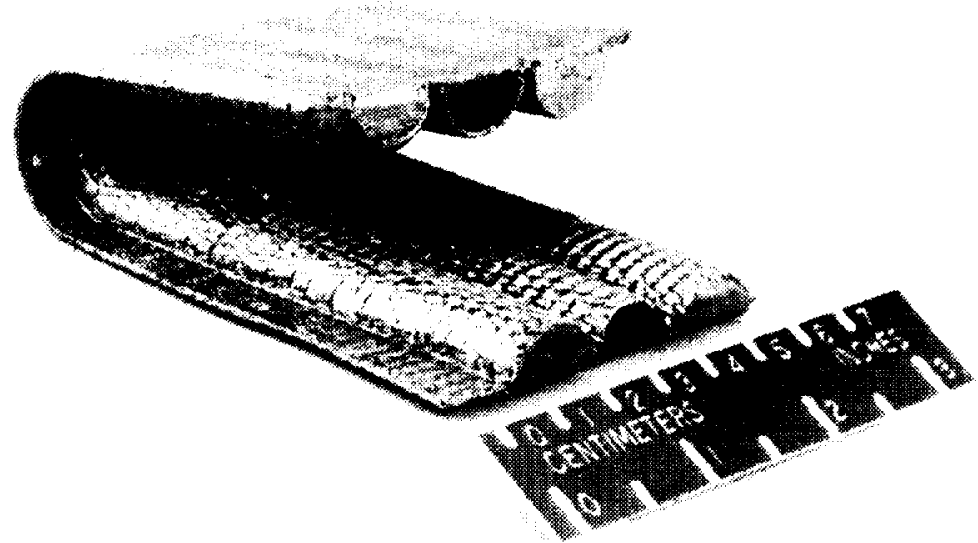

Figure 4: Photograph of Mo-Re nose section and similarly shaped machined graphite embedded in $\mathrm{C} / \mathrm{C}$.

To evaluate the ability to embed leading-edge-shaped heat pipes in $\mathrm{C} / \mathrm{C}$, a truncated heat-pipe container (just the nose section) was embedded in $\mathrm{C} / \mathrm{C}$ along with two pieces of graphite machined to the same shape as the Mo-Re nose section, as shown in Figure 4. The goal was to obtain experience embedding curves tubes in $\mathrm{C} / \mathrm{C}$ prior to embedding actual heat pipes. The graphite and Mo-Re tubes were inserted into a 3-D woven carbon preform (T-300 fibers) and the preform was then densified by Carbon-Carbon Advances Technologies (C-CAT), Fort Worth, TX. Tooling was used on both the inner and outer surface of the leading-edge component. Grafoil ${ }^{\circledR}$, a soft carbon layer, was bonded to the metallic tube with superglue prior to inserting it in the woven preform.

\section{Results and Discussion}

A single "D-shaped" cross section heat pipe in the shape of a leading edge was fabricated and tested at LANL. Several fabrication issues were resolved in the fabrication of the heat-pipe container and the wick. After fabrication, the heat pipe was tested at LANL using induction heating in a vacuum chamber. Premature failure of the heat pipe occurred due to electrical discharge from the induction heating concentrator to the heat pipe. A discussion of the fabrication, testing, and failure follows.

\section{Fabrication}

Due to the small leading-edge radius of 0.5 in., fabrication of the nose region of the heat pipe was challenging. The "J-tube" heat pipe has a "D-shaped" cross section and is shaped like a leading edge, but has only a short leg on one side of the nose region, and a long leg on the opposite side of the nose region. Several techniques were evaluated to fabricate the nose region of the heat pipes. Bending the "D-shaped" tube to the desired radius was not found to be feasible, nor was bending sections and then welding the nose together. The technique that was finally decided upon was to machine the nose 
components out of a solid piece of Mo-41Re and weld them together to form the nose region. Figure 5 is a photograph of the two nose section pieces individually and welded together with the tubing on both sides. The end plugs and a cover to be placed over the fill tube are also shown in the photograph. The machining, tube drawing, and welding were performed by Thermo Electron Tecomet, Wilmington, MA.

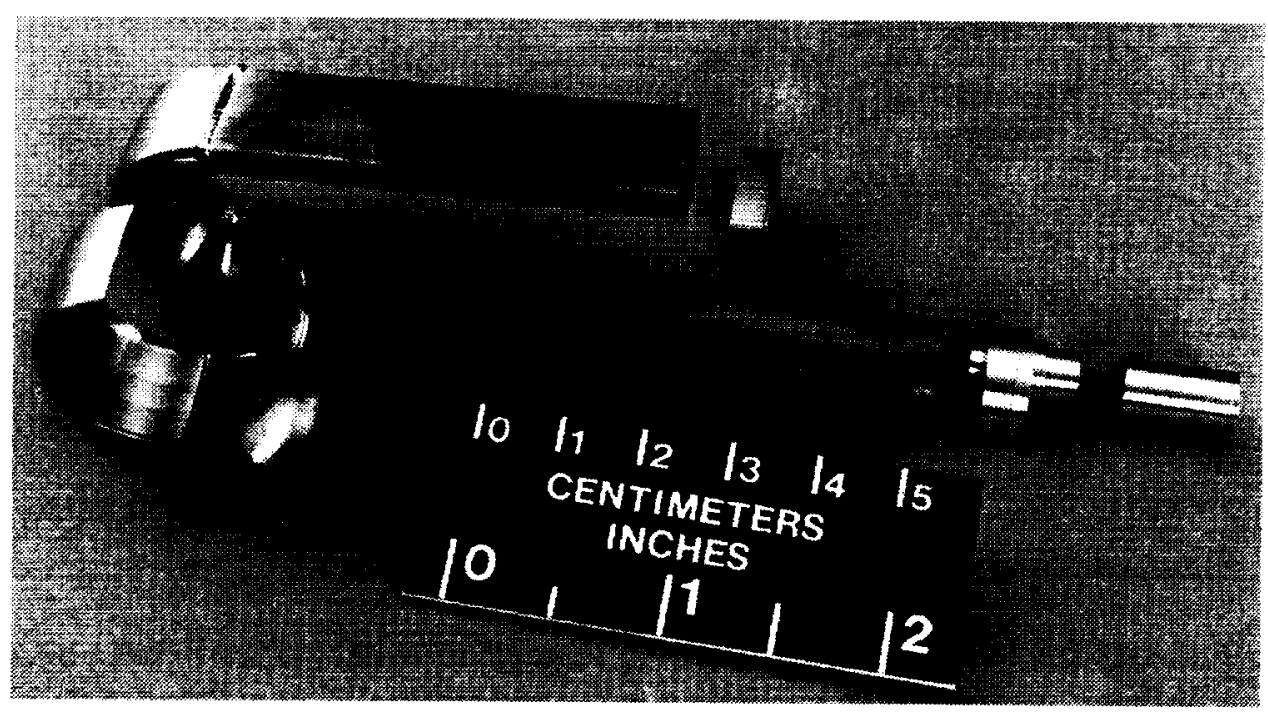

Figure 5: Photograph of the individual machined nose components and the completed nose assembly with the end plugs and fill tube cover.

The artery was fabricated by wrapping three layers of $400 \times 400$ mesh Mo-5Re screen around a 0.125 -in. outer diameter steel mandrel which was held in place with a 0.003 -in-diameter steel wire spirally wrapped the length of the artery. The steel mandrel/screen assembly was inserted into a 0.25 -in. outer diameter by 0.035 -in. wall steel sheath. The steel sheath was drawn down to a 0.210-in. outer diameter. After the final draw, the assembly was immersed in a water/hydrochloric solution and the steel mandrel, sheath, and wire were dissolved leaving the formed screen artery.

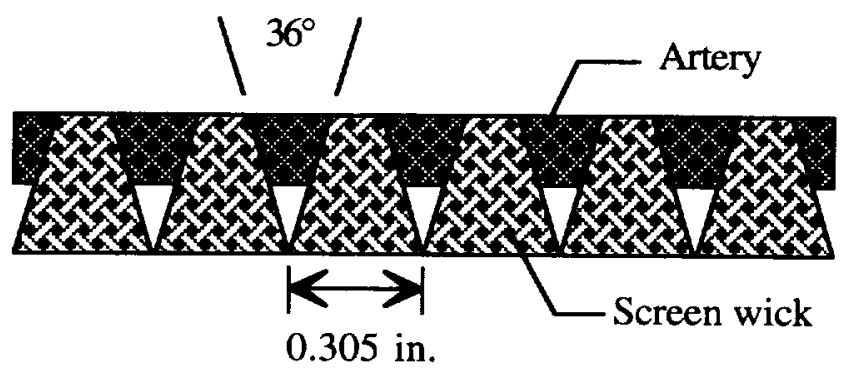

Figure 6: Schematic diagram of the dimensions of the artery prior to bending for fabrication of the nose section.

The screen wick was fabricated by wrapping the first two layers of $400 \times 400$ mesh screen over a copper mandrel that had been machined to the wick's final shape. The artery was placed over the first two layers of screen and the final two layers of screen 
were wrapped over the mandrel and artery and the edge of the final wrap was spot welded the length of the wick. The assembly was then slid off the copper mandrel.

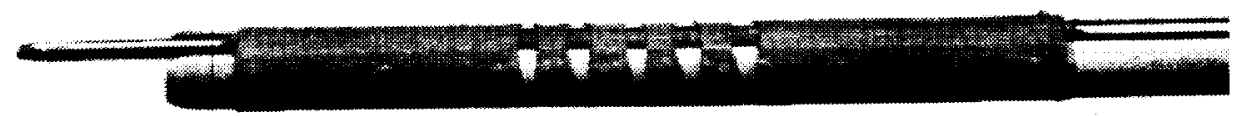

Figure 7: Photograph of the nose portion of the wick on a mandrel.

Portions of the screen wick were removed in the nose portion of the wick as illustrated in Figure 6. This allowed the screen wick to bend and still maintain a continuous artery through the nose section of the heat pipe. The angle of the screen that was cut out was $36^{\circ}$, with a 0.305 -in. spacing between the cut regions on the outside surface. A photograph of the nose portion of the screen wick on a mandrel with a solid rod used to support the artery is shown in Figure 7.

A photograph of the inside bend of the heat pipe with the screen wick being wrapped around is it shown in Figure 8. In the figure the region of the wick where sections were cut out in the nose region can be seen. The straight sections of the wick are also shown. The nose section of the wick was formed by bending the wick assembly on the machined parts that form the nose section. Figure 9 shows the screen wick in its final configuration. The artery can be seen extending from the upper portion of the wick in the photograph.

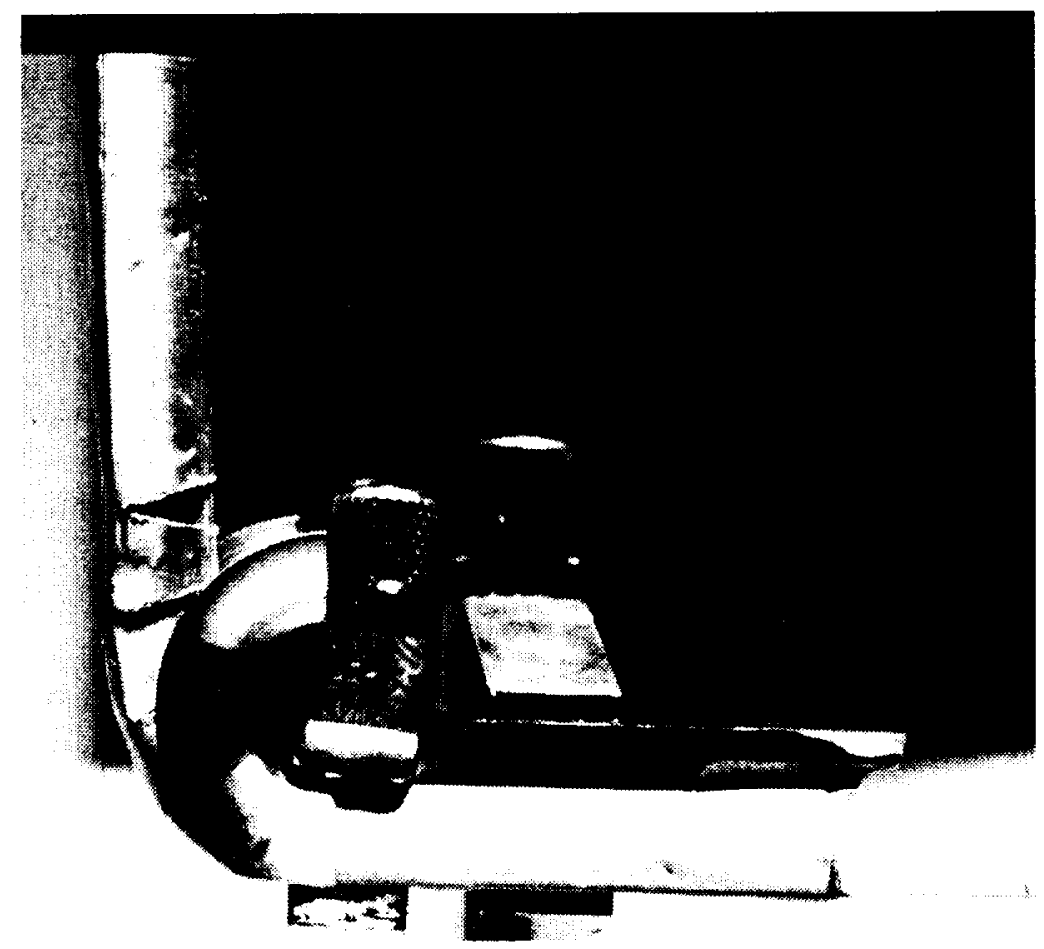

Figure 8: Photograph of the screen wick in the nose region prior to bending around the machined nose part. 


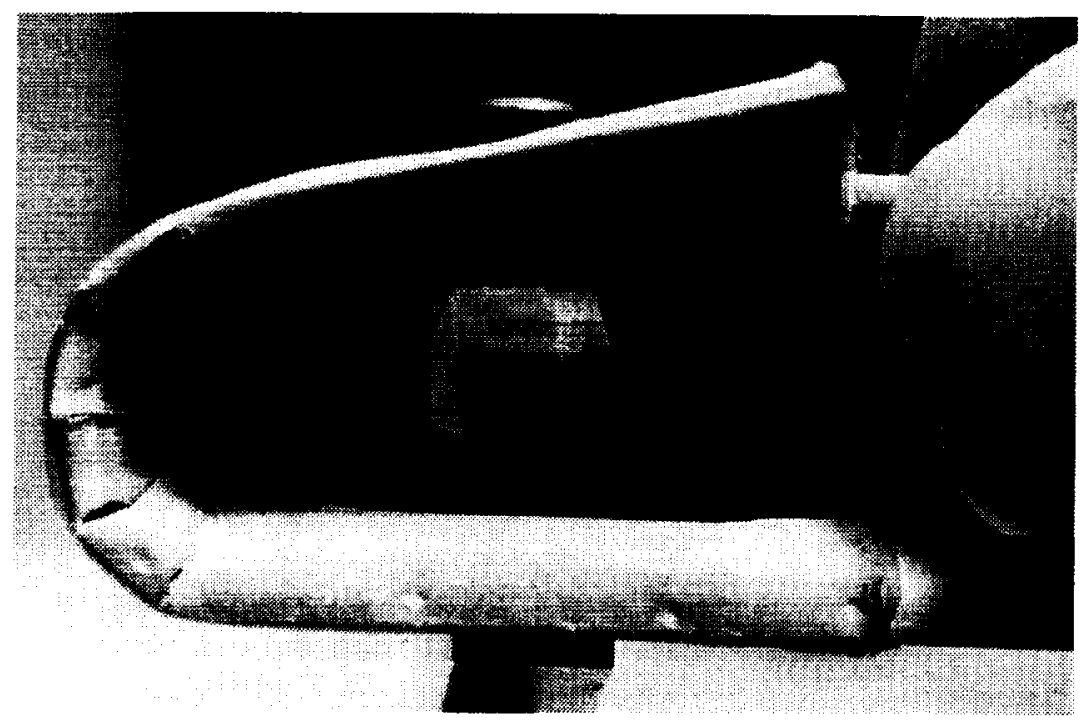

Figure 9: Photograph of the screen wick in the nose region after fabrication.

\section{Testing}

After the heat pipe was assembled, $0.017 \mathrm{lb}(7.5 \mathrm{~g})$ of lithium were loaded into the heat pipe by distillation, as described in ref. 20 . The heat pipe was wet-in at $3170^{\circ} \mathrm{F}$ for 53 hours in a vacuum furnace. After wet-in, the heat pipe was oriented with the short leg of the heat pipe on the top and the long leg on the bottom and placed in a vacuum test chamber. An rf-induction coil/concentrator was used as the heat source. The heating device was designed to heat the entire width of the flat portion of the heat pipe for a chord length of $1.6 \mathrm{in}$. in the nose region. Initial tests heated the heat pipe to $1700^{\circ} \mathrm{F}$, resulting in a heat flux of approximately $362 \mathrm{Btu} / \mathrm{ft}^{2}-\mathrm{s}$. Figure 10 shows a photograph of the heat pipe during initial testing in the vacuum chamber. The induction heating concentrator can be seen on the outside of the nose region. In the photograph, the nose region is hotter than the rest of the heat pipe since the photograph was taken during startup.

In order to put enough heat into the heat pipe to heat the entire heat pipe to operating temperatures, a large amount of heat was required in the nose region. During initial testing of the heat pipe, the inside surface of the nose region remained hotter than the outside "heated" surface. The hot spot was due to the fact that the inside surface was heated by the induction heating but was not adequately cooled by the liquid lithium. The heating distribution resulted from the nature of induction heating, which inductively heats the entire nose region. The inside surface of the nose region was not cooled adequately due to the discontinuous wick, as shown in Figure 7. In the actual application, inadequate cooling of the inside surface would not be a problem since it would not be subjected to the aerodynamic heating.

The approach taken to solve the hot spot problem was to insulate the inside, curved surfaces of the heat pipe. In actual operation, the inside surface would radiate away only a minimal amount of heat. If the inside surface were insulated, then less heat input would 
be required to bring the heat pipe up to operating temperatures. With less heating in the nose region, the inside surface of the nose region might not develop a hot spot.

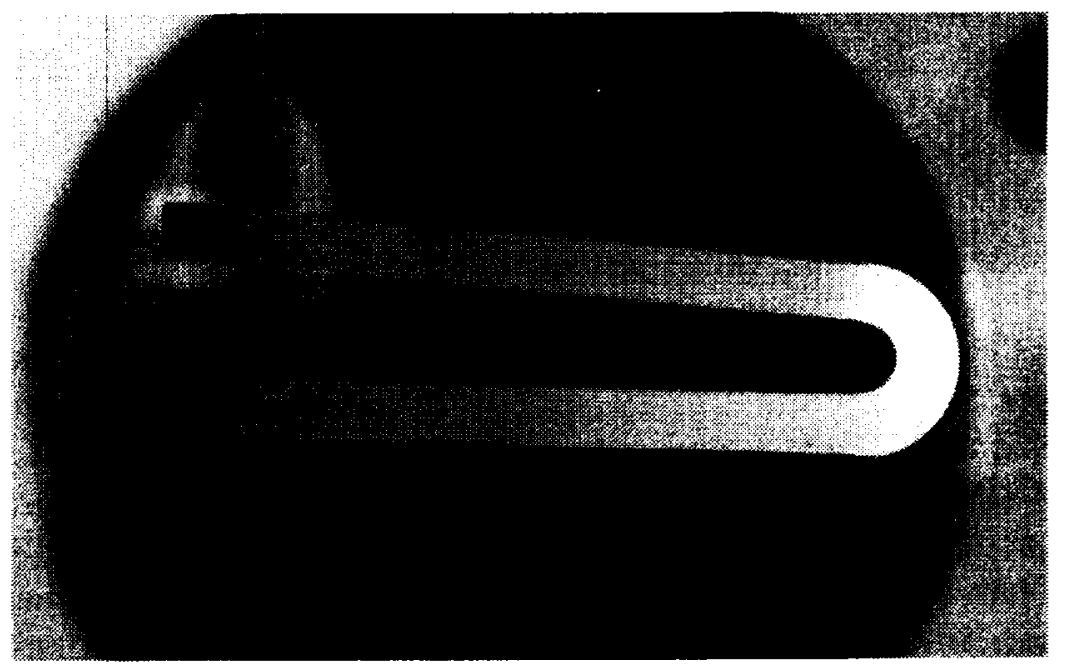

Figure 10: Photograph of the heat pipe during initial testing with induction heating concentrator in the nose region.

The heat pipe was mounted inside the vacuum chamber with the nose region facing a new rf concentrator and coils, as shown in Figure 11. RF power was induced from the coils to the concentrator and then to the heat pipe. Porous refractory insulation that had been baked for several days at $1880^{\circ} \mathrm{F}$ was placed on inward facing surfaces to reduce radiative coupling between the heat pipe and the chamber walls. In the photograph, the insulation is seen to cover only the curved portion of the heat pipe. (The photograph in Figure 11 was taken after the accident to be discussed later. Holes seen in the copper cooling coils resulted from the accident.)

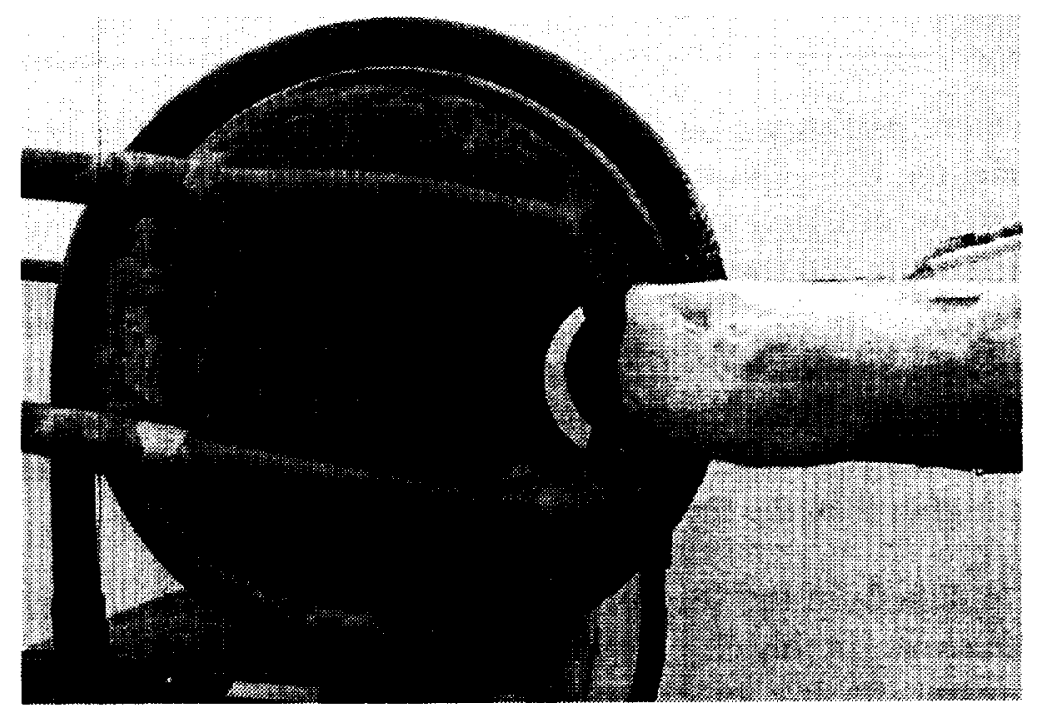

Figure 11: Photograph of insulated heat pipe positioned in rf concentrator. 


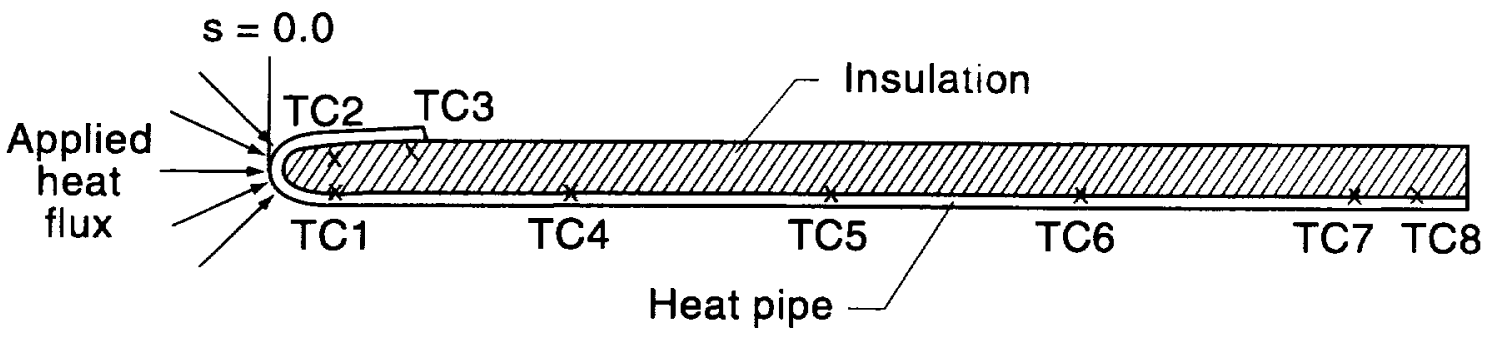

Figure 12: Schematic drawing of the insulated heat pipe with thermocouples.

W/W-Re thermocouples were placed on the heat pipe by strapping them down with wire since experience welding thermocouples on a different Mo-Re heat-pipe container was unsuccessful. ${ }^{18}$ Though the temperature uncertainty was greater than if the thermocouples were welded, the operation of the heat pipe was not compromised by the instrumentation. Two thermocouples were located on the upper surface (the short leg), and six were located on the (long leg) lower surface. The thermocouple locations relative to the stagnation line are shown in Figure 12 and listed in Table 1, where the negative numbers refer to the short leg on the upper surface.

Table 1: Location of Thermocouples

\begin{tabular}{cc}
\hline & \\
Thermocouple & Position, $\mathrm{s}$, in. \\
\hline 1 & 1.2 \\
2 & -1.4 \\
3 & -3.5 \\
4 & 8.1 \\
5 & 14.9 \\
6 & 21.8 \\
7 & 28.7 \\
8 & 30.7 \\
\hline
\end{tabular}

Four tests were performed on the heat pipe prior to catastrophic failure of the heat pipe. In each case, the heat pipe was started up over the course of several hours. Though neither isothermal nor design temperatures were obtained, the heat pipe was operational. Due to outgassing from the insulation, high heat fluxes were not obtained. Figure 13 shows the start-up data for the heat pipe during the first test with insulation. Thermocouples 1 and 2 indicated similar temperatures since they were similar distances from the stagnation line. Since the thermocouples were strapped onto the heat pipe, the accuracy of the readings is unknown. However, it is likely that the actual heat-pipe temperature was higher than the thermocouple reading.

The start up data from the second test is shown in Figure 14. As in Figure 13, the start up was quite slow. In this case, the heat flux was reduced after about six hours, and then increased again. Steady state temperatures were then obtained, but the heat flux values were too low to attain isothermal operation. The start-up data from test three is shown in Figure 15. Though the start-up was slower, the maximum temperatures attained were similar. 


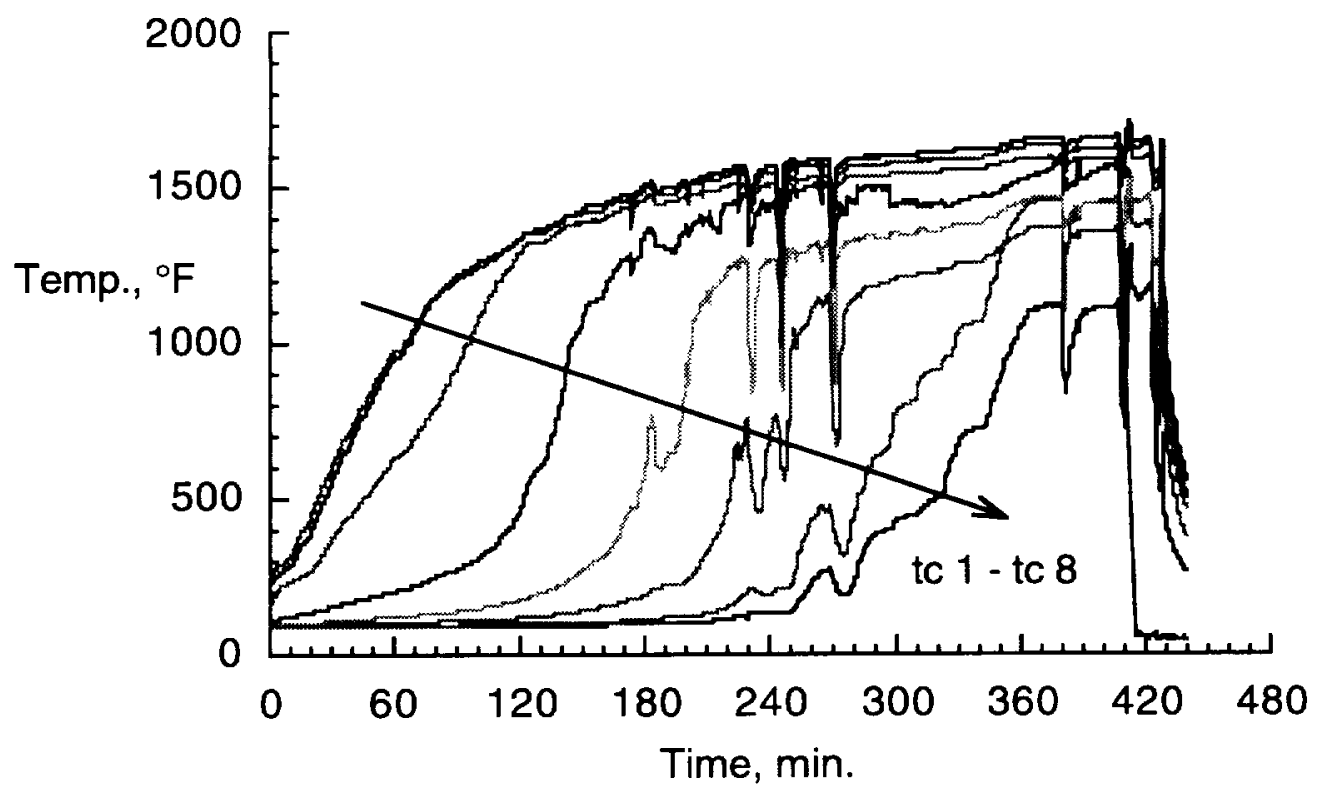

Figure 13: Start-up data for heat pipe during initial test.

The start-up data for the final test is shown in Figure 16. The temperature readings for thermocouples $3-8$ seem to flatten out at lower temperatures than in the three prior tests. The cause of this is unknown. Approximately 250 minutes into the test, electrical discharge was noticed in the vacuum chamber and the induction heating concentrator and the heat pipe were destroyed.

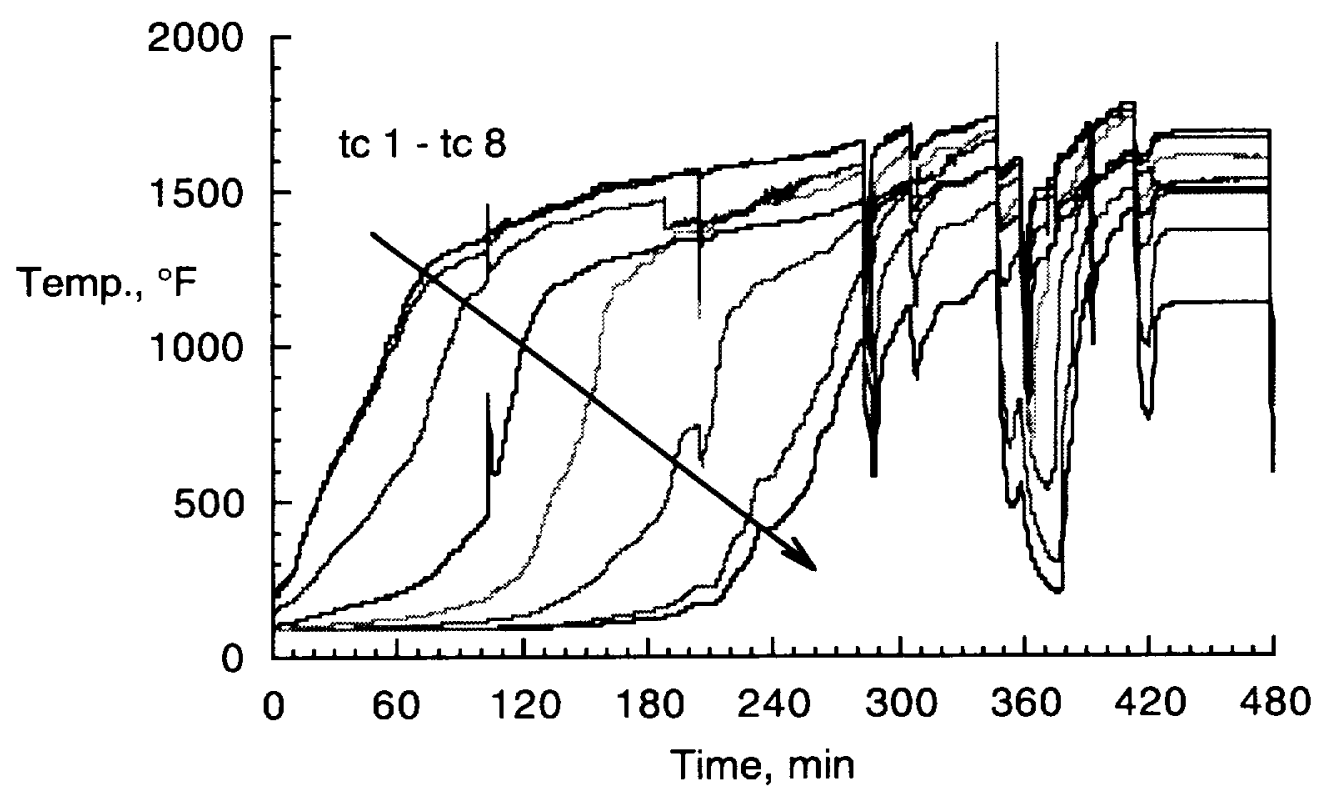

Figure 14: Start-up data for heat pipe during second test. 


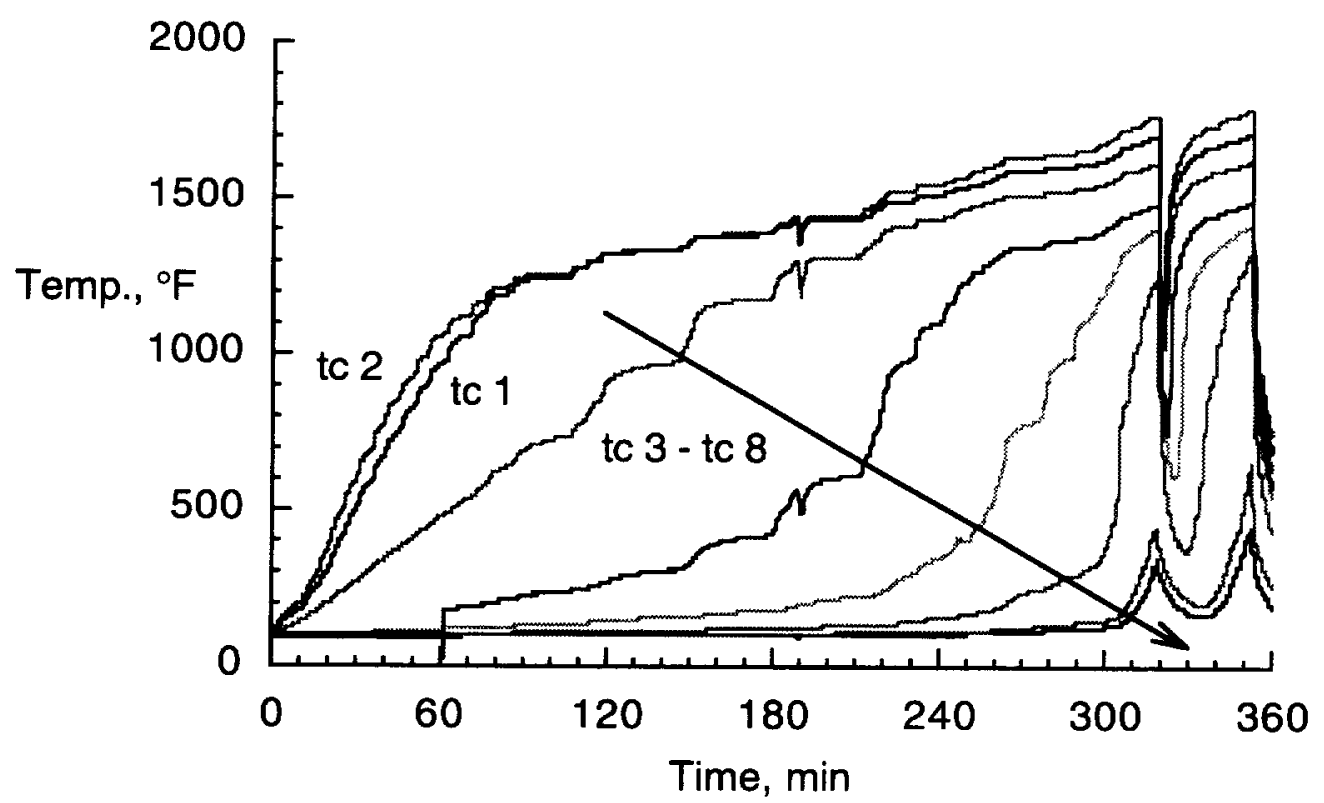

Figure 15: Start-up data for heat pipe during third test.

In the first two tests, the heat pipe was operational over most of the entire length, while in two later tests, it was operational only over a portion of the heat-pipe length, as shown in Figure 17. The data in the figure represent the highest temperatures obtained at a given time during the particular test, not steady state values. The stagnation line is located at $\mathrm{s}=0 \mathrm{in}$. The data for test 1 does not include a temperature at $\mathrm{s}=8.1 \mathrm{in}$. since the thermocouple was not functioning properly at the time. From the figure, it is apparent that the leading edge shaped heat pipe did operate as expected, though design temperatures and heat fluxes were not obtained.

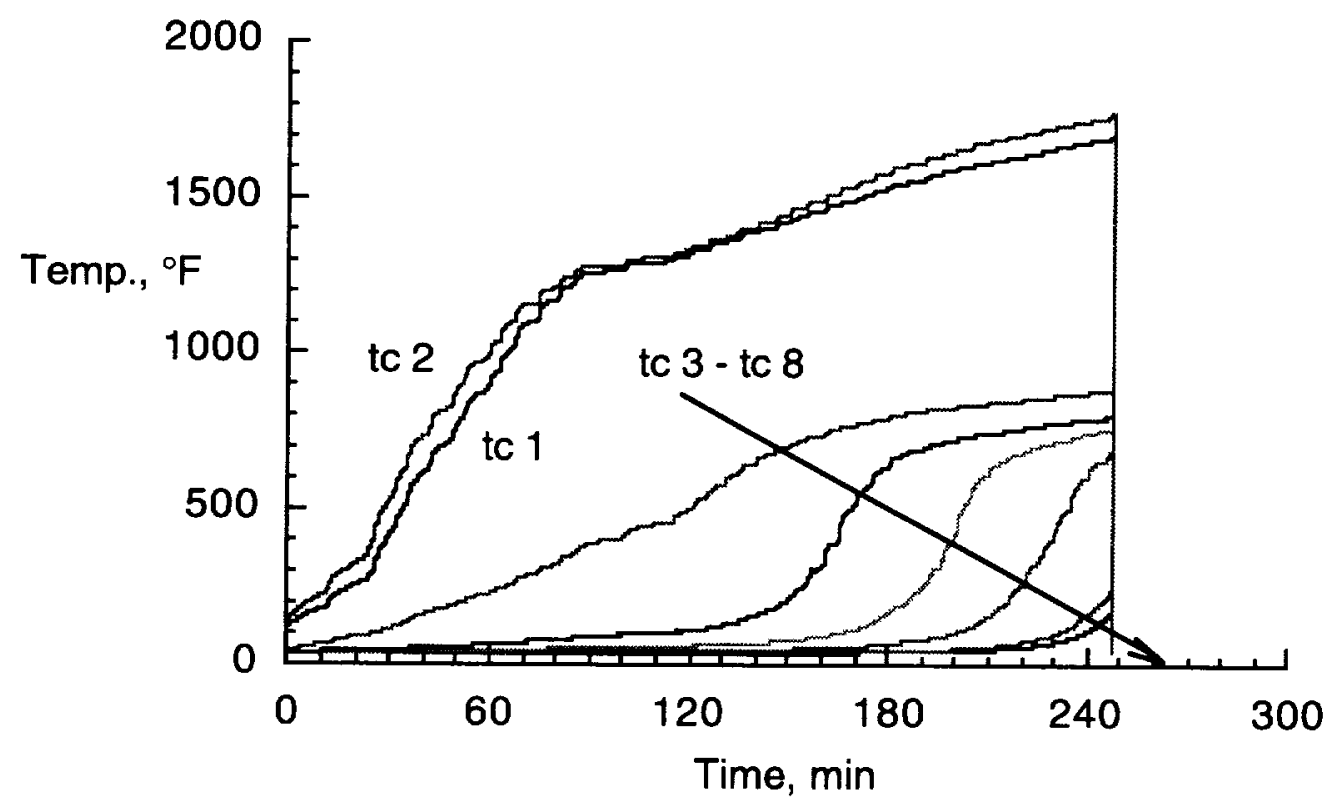

Figure 16: Start-up data for heat pipe on final test. 


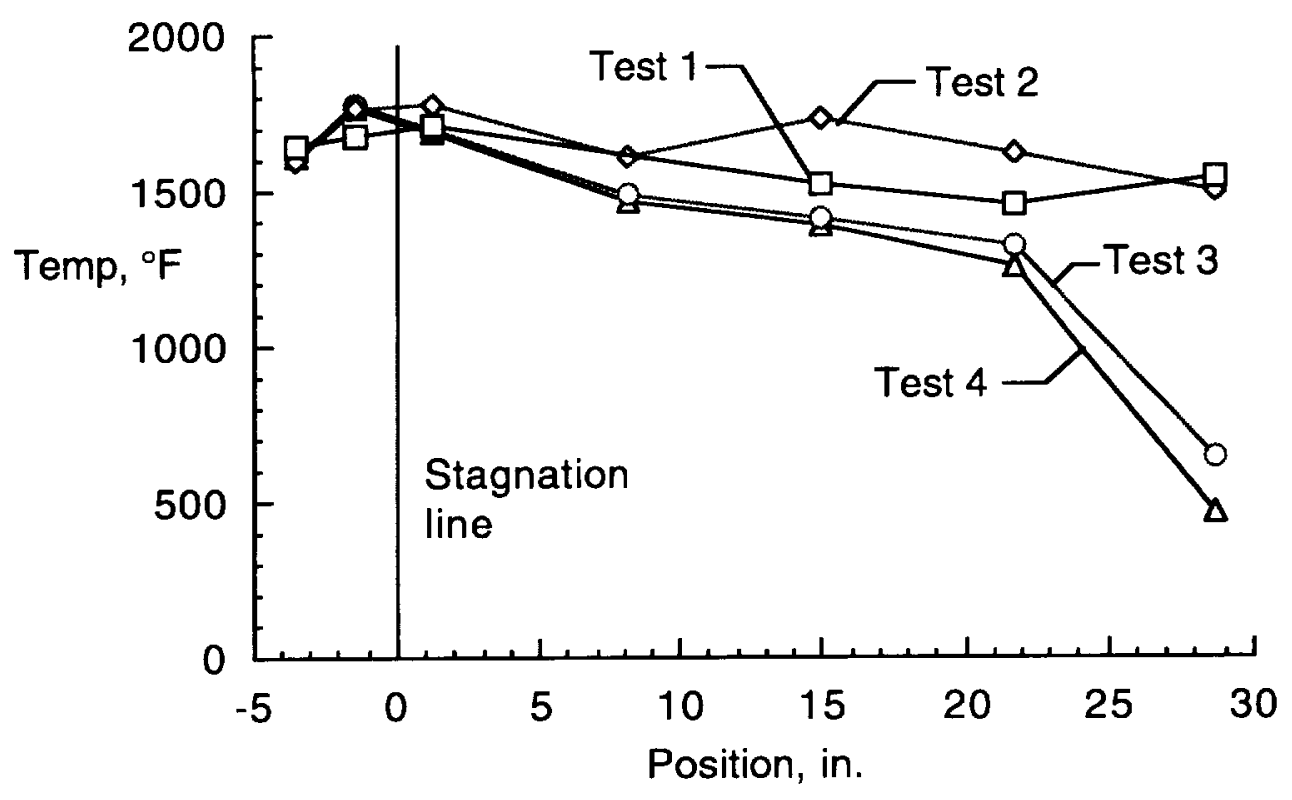

Figure 17: Maximum heat-pipe temperatures during the four tests.

\section{Failure}

During the third test, the heat pipe was started from the frozen state over $6 \mathrm{~h}$. An indication of ionization was occasionally observed as the heat pipe grew warmer. This ionization was attributed to outgassing of volatiles from the insulation. Power was increased and the chamber pressure was monitored. When the chamber pressure neared $1 \times 10^{-4}$ torr the power was kept constant until the insulation had outgassed volatiles at that temperature and the chamber pressure fell below $2 \times 10^{-5}$ torr. After reaching $1296^{\circ} \mathrm{F}$, the heat pipe was shut down after repeated discharge (violet glow) in the vacuum chamber.

During the fourth and final test, the heat pipe was again started from the frozen state. After $250 \mathrm{~min}$, light suddenly flashed from the chamber. The rf generator was shut down within $10 \mathrm{~s}$ of the first flash of light. After the generator was shut down, the heat pipe and chamber were inspected. High vacuum was lost and standing water was seen on the bottom of the vacuum chamber. The chamber was then opened. Large holes were found on the upper and lower heat-pipe surfaces. Numerous holes penetrated the copper rf coil wall in the turn nearest the heat pipe.

The heat pipe most likely failed when volatiles (water vapor) in the refractory insulation outgassed, raising the gas pressure in the if coil-heat pipe gap above 0.1 torr. A violet-colored electric discharge followed between the if coil (anode) and the heat pipe (cathode). At some point, the transfer of charge carriers across the gas gap was apparently sufficient to form multiple holes in the copper if coil.

After the failure, a blue-colored coating was seen on grounded copper surfaces inside the vacuum chamber. The hypothesis is that the blue coating is plated 
molybdenum. If true, this suggests significant removal of molybdenum during the discharge. The heat-pipe wall was 0.010 -in. thick where the holes formed.

An order of magnitude estimate of the time required to form a hole the size found in the copper $\mathrm{rf}$ coil, assuming a $1 \mathrm{kV}$ potential between the coil and heat pipe, resulted in a time estimate of 1 second. Once a hole formed in the rf coil, 70 psi water flowed into the chamber and onto the heat pipe. Whether the large holes formed in the heat pipe and coil before or after the water started flowing is uncertain, but probably unimportant. The water resulted in a sudden rise in chamber pressure and reacted with the lithium from the heat pipe.

In future tests, it is recommended that refractory insulation with high vapor pressure contents be avoided. Foil radiation shields are one possibility for insulating the surfaces. This would pose a potential problem with inducing if onto the foil, but that would be a less sever problem than the one experienced here.

\section{Concluding Remarks}

A leading-edge-shaped Mo-Re heat pipe was fabricated and tested. Several container and wick fabrication issues were resolved that arose due to the small 0.5-in. leading-edge radius. The heat pipe was tested in a vacuum chamber with induction heating, but prematurely failed due to electrical discharge between the induction heating concentrator and the heat pipe. The heat pipe did start up as expected and operated as a heat pipe, however, not at design heat fluxes and temperatures. Though a testing anomaly caused premature failure of the heat pipe, successful startup and operation of the heat pipe are key steps toward the development of heat pipes for cooling sharp leading edges.

\section{Acknowledgment}

The authors would like to thank the Thermal Structures Branch at NASA Langley Research Center for funding this work under Contract No. NAS1-96014.

\section{References}

${ }^{1}$ Silverstein, C. C., "A Feasibility Study of Heat-Pipe-Cooled Leading Edges for Hypersonic Cruise Aircraft," NASA CR 1857, Nov. 1971.

${ }^{2}$ Niblock, G. A., Reeder, J. C., and Huneidi, F., "Four Space Shuttle Wing Leading Edge Concepts," Journal of Spacecraft and Rockets, Vol. 11, No. 5, 1974, pp. 314-320.

${ }^{3}$ Alario, J. P., and Prager, R. C., "Space Shuttle Orbiter Heat Pipe Application," NASA CR 128498, April 1972.

${ }^{4}$ Anon., "Study of Structural Active Cooling and Heat Sink Systems for Space Shuttle," NASA CR 123912, June 1972.

${ }^{5}$ Anon., "Design, Fabrication, Testing, and Delivery of Shuttle Heat Pipe Leading Edge Test Modules," NASA CR 124425, April 1973.

${ }^{6}$ Camarda, C. J., "Analysis and Radiant Heating Tests of a Heat-Pipe-Cooled Leading Edge," NASA TN D-8468, Aug. 1977. 
${ }^{7}$ Camarda, C. J., “Aerothermal Tests of a Heat-Pipe-Cooled Leading Edge at Mach 7,” NASA TP-1320, Nov. 1978.

${ }^{8}$ Camarda, C. J., and Masek, R. V., "Design, Analysis and Tests of a Shuttle-Type Heat-Pipe-Cooled Leading Edge," Journal of Spacecraft and Rockets, Vol. 18, No. 1, 1981, pp. 71-78.

${ }^{9}$ Peeples, M. E., Reeder, J. C., and Sontag, K. E., "Thermostructural Applications of Heat Pipes," NASA CR 159096, June 1979.

${ }^{10}$ Boman, B. L., Citrin, E. C., Garner, E. C., and Stone, J. E., "Heat Pipes for Wing Leading Edges of Hypersonic Vehicles," NASA CR 181922, Jan. 1990.

${ }^{11}$ Boman, B. L., and Elias, T., "Tests on a Sodium/Hastelloy X Wing Leading Edge Heat Pipe for Hypersonic Vehicles," AIAA Paper 90-1759, June 1990.

${ }^{12}$ Merrigan, M. A., Sena, J. T., and Glass, D. E., "Evaluation of a Sodium/Hastelloy$\mathrm{X}$ Heat Pipe Designed to Cool the Wing Leading Edge of an Advanced Space Transportation System", Proceedings of the ASME Heat Transfer Conference, Houston, TX, August 1996, pp. 333-341.

${ }^{13}$ Clark, L. T., and Glenn, G. S., "Design Analysis and Testing of Liquid Metal Heat Pipes for Application to Hypersonic Vehicles", AIAA Paper 88-2679, June 1988.

${ }^{14}$ Wojcik, C. C., "Niobium Alloy Heat Pipes for Use in Oxidizing Environments", $8^{\text {th }}$ Symposium on Space Nuclear Power Systems, Albuquerque, NM, January 1991, pp. 326-333.

${ }^{15}$ Wojcik, C. C., and Clark, L. T., “ Design, Analysis, and Testing of Refractory Metal Heat Pipes Using Lithium as the Working Fluid", AIAA Paper 91-1400, June 1991.

${ }^{16}$ Glass, D. E., and Camarda, C. J., "Preliminary Thermal/Structural Analysis of a Carbon-Carbon/Refractory-Metal Heat-Pipe-Cooled Wing Leading Edge," Thermal Structures and Materials for High Speed Flight, edited by E. A. Thornton, Vol. 140, Progress in Astronautics and Aeronautics, AIAA, Washington, DC, 1992, pp. 301-322.

${ }^{17}$ Glass, D. E., Camarda, C. J., Sena, J. T., and Merrigan, M. A., "Fabrication and Testing of Heat Pipes for a Heat-Pipe-Cooled Leading Edge," AIAA 97-3876, August 1997.

${ }^{18}$ Glass, D. E., Merrigan, M. A., and Sena, J. T., "Fabrication and Testing of Mo-Re Heat Pipes Embedded in Carbon/Carbon," NASA/CR-1998-207642, March 1998.

${ }^{19}$ Glass, D. E., Camarda, C. J., and Merrigan, M. A, Refractory-Composite/HeatPipe-Cooled Leading Edge, U.S. Patent No. 5,720,339, Feb. 1998.

${ }^{20}$ Merrigan, M. A., Keddy, E. S., and Sena, J. T., "Transient Performance Investigation of a Space Power System Heat Pipe”, AIAA Paper 86-1273, June 1986. 


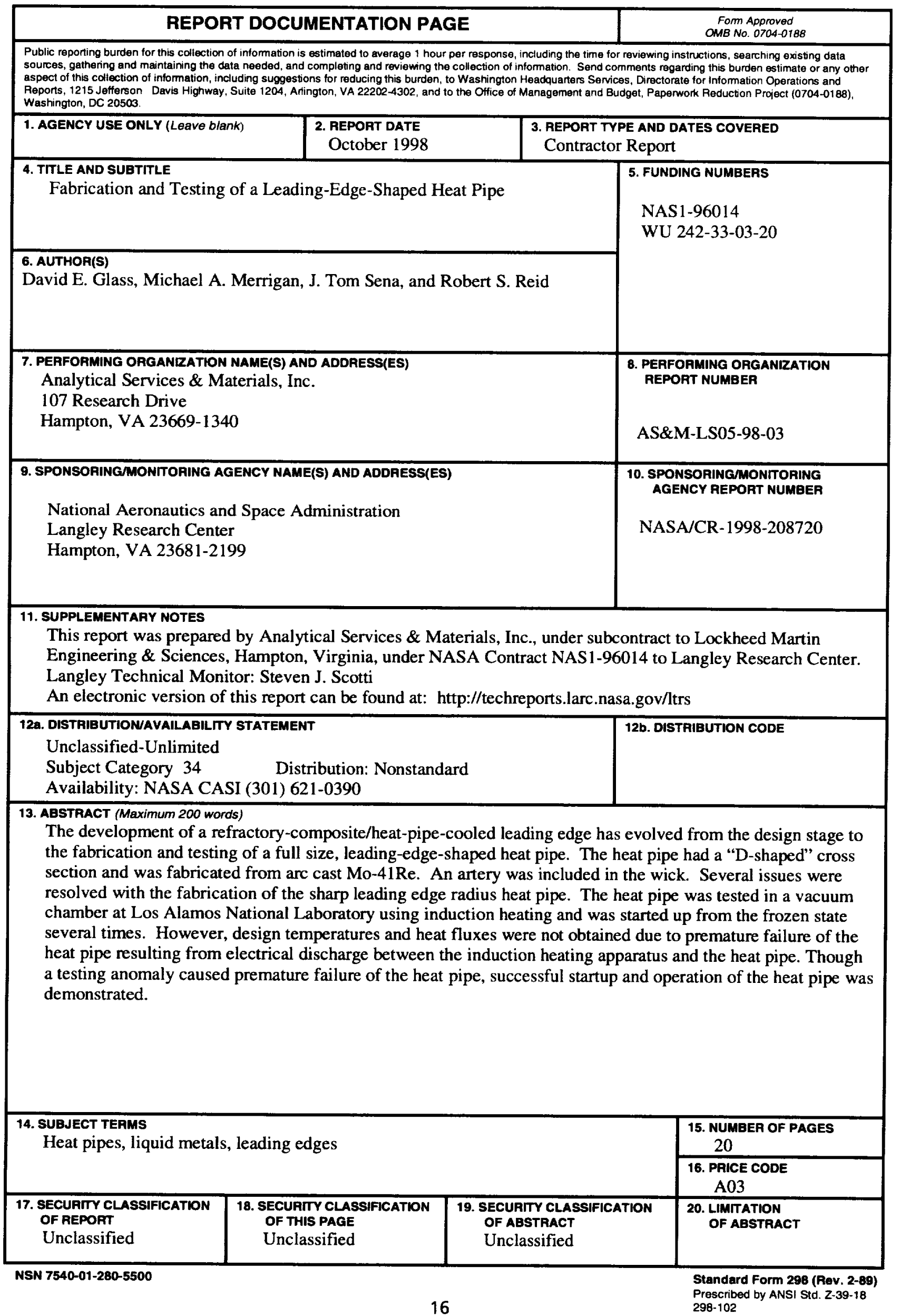

